\title{
Reducing the Impact of Wind Load with Shape of High Rise Buildings
}

\author{
Nasra Mohammed Nasser Al- \\ Middle East College \\ Azri \\ Sachin Kuckian \\ Himanshu Gaur \\ Middle East College \\ Middle East College
}

Recent Years, Many high rise buildings are being constructed across the world due to the increase in population. From the design point of view, lateral load such as earthquake and wind load should be taken into consideration while designing process. Architectural design of buildings sometimes leads towards difficult and unusual shape that challenges structural designers. The objective of this study is to assess the building behavior when subjected to wind load. To achieve this objective, different shapes of building such as pentagonal, triangular and circular building are assessed for stability. Parameters such as storey drift and lateral displacement are considered in order to find most effective and stable shape. The computer program ETABS is used for analysis. As the height of the building increases, wind load effect becomes significant and should be considered for designing. This could also be achieved by selecting most stable shape and appropriate structural system for tall buildings.

\section{INTRODUCTION}

As today the population in urban areas is increasing day by day and the space is required for their work place and residence so there was a demand for vertical evolution of cities. During designing of structures, the vertical load only considered which come from gravity but due to the increasing in height of buildings the lateral load must be taken into consideration such as wind load. There are many high rise buildings constructed among the world as well as many researchers study the effect of wind load on tall buildings. Because of sensitive structural system of high rise buildings, it's very important to consider the influence of lateral load produced from wind load in designing in order to prevent collapse and damage the structure. Modernistic buildings provided by high efficiency of structural system and high quality materials in order to be more flexible and stable building. There are three building shapes considered for this study which are triangular, pentagonal and circular. The compression between all three shapes has been done in order to choose the most stable shape that has less affect induced by wind load. In literature review section there are many literatures have been done in reducing the wind load to the different shapes of high rise buildings. In this paper, the methodology section will consist the methods that helps to achieve the requirement and goals of the project are provided with the parameters used in software for analysis part. The result and discussion chapter consist of charts and discussion for each. Also, plotted graph for the compression between different shapes of buildings has been done in order to choose the best shape in reducing the response of wind load.

There are many objectives of this study which are:

- To study the high rise building behaviour when subjected to wind load.

- To find alternate solutions in order to reduce the wind load on high rise buildings.

- To investigate the effect of building shape like triangular, Pentagonal and circular on the response to wind. 
- To compare different shapes of building with its effect to the response to wind.

\section{METHODOLOGY}

The cross-sectional shapes of prototype high rise buildings have been considered in this project are triangular, circular and pentagonal having same plan area $1200 \mathrm{~m}^{2}$ with $\mathrm{G}+19$ storey. All tall buildings prototypes have been modeled by using Auto CAD 2016 for making 3D model for beam and column and then import it to E-tabs 2016 for slab modelling and defining section properties as well as assigning loads. Furthermore, Excel software has been used in order to make compression between three building shapes through different parameters to get the most stable building shape. The height of all prototypes buildings is constant $58.3 \mathrm{~m}$ where $3.2 \mathrm{~m}$ for ground floor and 2.9 for other floors. The parameters considered for this study have been shown in table 1. Basic wind speed has been taken according to Oman map where its value $31 \mathrm{~m} / \mathrm{s}$ (Al-Nuaimi, Mohsin and AlRiyami 2014). The parameters that studied in this paper are storey displacement and storey drifts:

- Storey displacement: is the movement of building storey related to the base due to the lateral load (Satish 2016).

- Storey drift: is the lateral displacement or drift of one level to the level below or above (Mercado 2016).

\begin{tabular}{|l|l|}
\hline No. of storey & $\mathrm{G}+19$ \\
\hline Ground floor height & $3.2 \mathrm{~m}$ \\
\hline Storey height & $2.9 \mathrm{~m}$ \\
\hline Basic wind speed & $31 \mathrm{~m} / \mathrm{s}=69.34 \mathrm{mph}$ \\
\hline Shape of buildings & Triangular, Pentagonal, and circular. \\
\hline Plan area & $1200 \mathrm{~m} 2$ \\
\hline Thickness of slab & $0.25 \mathrm{~m}$ \\
\hline Thickness of wall & $0.2 \mathrm{~m}$ \\
\hline Beam size & $0.3 \mathrm{~m} \times 0.7 \mathrm{~m}$ \\
\hline Column size & $1 \mathrm{~m} \times 1 \mathrm{~m}$ \\
\hline Left size & $2 \mathrm{~m} \times 2 \mathrm{~m}$ \\
\hline Material Properties & \\
\hline Grade of concrete & $\mathrm{M} 35$ \\
\hline Grade of steel & Fe500 \\
\hline Dead load intensities & \\
\hline DL on slab & $2 \mathrm{KN} / \mathrm{m} 2$ \\
\hline Live load intensities & \\
\hline LL on floors & $3 \mathrm{KN} / \mathrm{m} 2$ \\
\hline LL on roof & $1.5 \mathrm{KN} / \mathrm{m} 2$ \\
\hline
\end{tabular}

Table 1. Parameters considered for the study.

\section{BUILDING MODELS}




\section{Journal of Student Research}

Fourth Middle East College Student Research Conference, Muscat, Sultanate of Oman



Figure 1. 3-D view of triangular building. 


\section{Journal of Student Research}

Fourth Middle East College Student Research Conference, Muscat, Sultanate of Oman

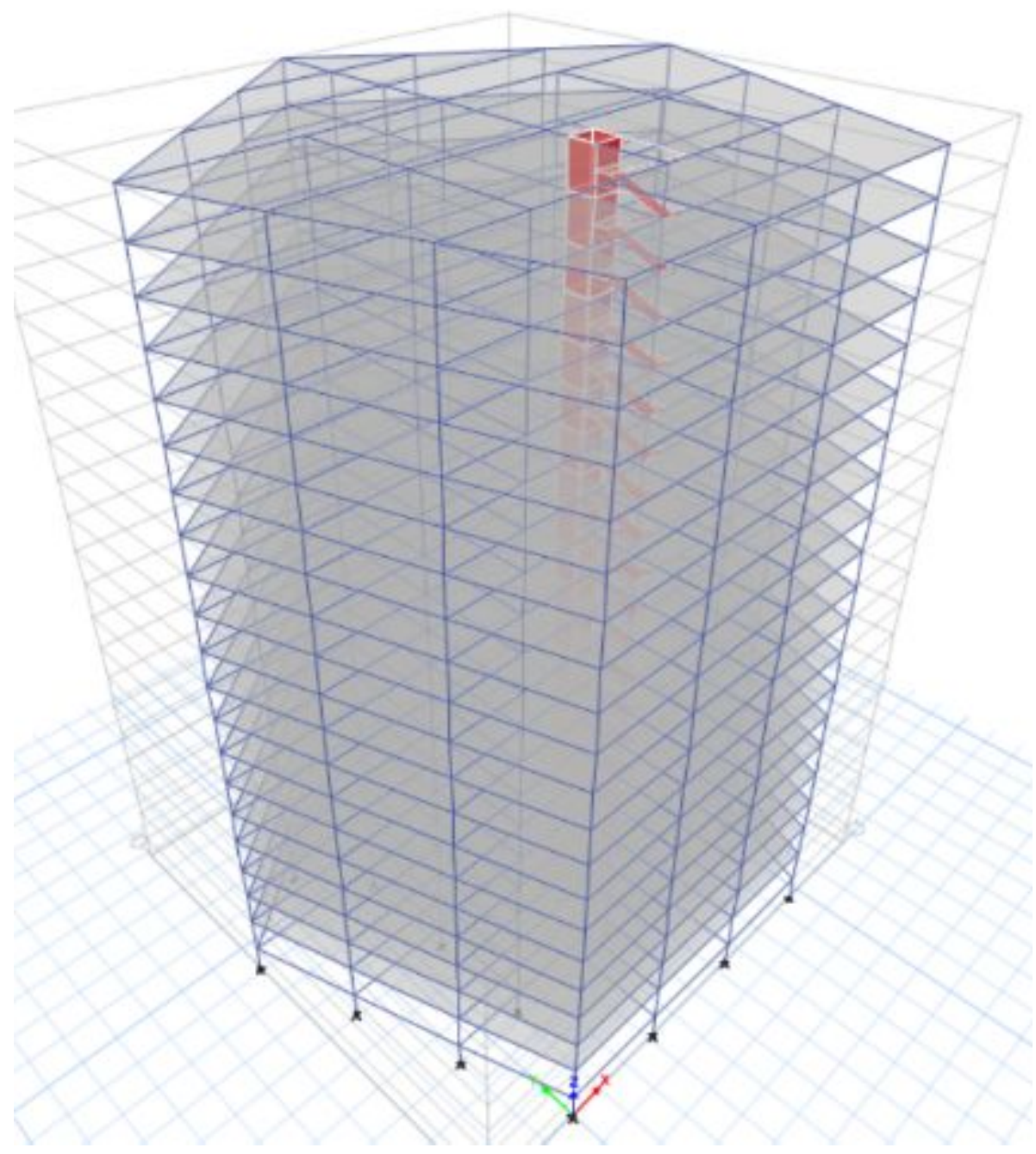

Figure 2. 3-D view of pentagonal building. 


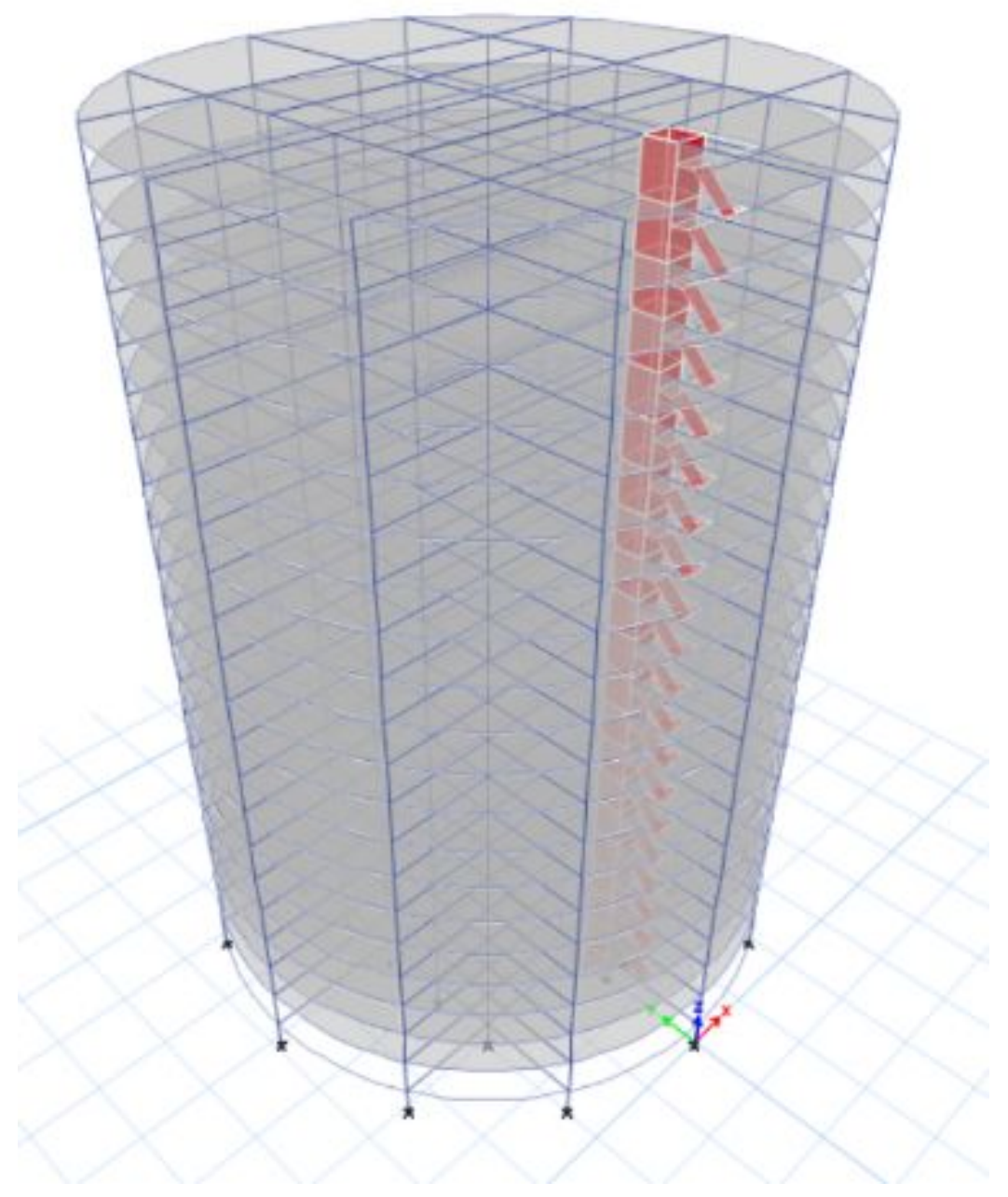

Figure 3. 3-D view of circular building.

\section{LITERATURE REVIEW}

The universal urban population is predicted to increase around $1.84 \%$ yearly in between 2015 2020. So this huge number of population in the world should be accommodated because there is no sufficient space on the ground. The design and analysis of tall buildings for lateral loads for example earthquake and wind load are issues that playing major role recently in designing of high rise building. This research studied about how the analyzing of wind load playing significant role in analysis and design of high rise buildings. This research carried out analysis of G+19 floors structure to understand its behavior when subjected to wind load. The parameters that focused on to study the behavior of the building are bending moment, axial force and shear force in column, storey drift, storey shear and displacement of building as well as stress in beam. The high rise building which has been chosen for the study is residential building with reinforced cement concrete formed. This model was created by using M40 grade to column and M30 for beam and slab. Floor load taken as per IS 875 (Part I \& II) and wind load taken by referring to IS 875-1987 and IS 456-2000 (Part V) with speed of $39 \mathrm{~m} / \mathrm{sec}$ as per IS 875 (Part III). It was found that when the wind load applied, the reinforcement column increasing while the axial force remains same on decreasing in which wind facing area. In addition, after applying wind load the stress in beam will increase. In order to make the structure stronger to resist wind load, both beam and column should have sufficient stiffness. Because of wind load, the longitudinal member like column increases in shear force. So, for designing building for wind load the storey shear should be taken into consideration. Also, at high storey of the building the lateral load of wind will be high. In high rise buildings, displacement will increase due to increase in wind pressure so this will create additional 


\section{Journal of Student Research}

stress in the members of the building (Patil, Mali and Talikoti 2015).

It's very important to consider the influence of lateral load produced from earthquake and wind load in designing of reinforced cement concrete structures, particularly for multi-storey building. There are many computer programs used for analyzing the structure behaviors when subjected to wind pressure. In this research, high rise buildings of five and ten storeys have been modeled by using ETABS software. This research also describes the effect of different height of building with the response to wind load. The meaningful of this paper is to evaluate the designing load of the structure which is applied to wind load in special region. For designing any structure, the loads acting on the structure should be indicated. The parameters that have been studied in this paper are axial force in column and both shear force and bending moment for beam and column. It was concluded from the research that the parameters for wind load influence any structure are the area applied to wind and the wind intensity realized by the code based on its location. In addition, it was found that the wind load increases with the height of the building. Also, the structures must be designed for forces obtained in different directions for critical forces of earthquake or wind (Sagar et al. 2015).

While the number of population is increasing year over year, the demand of tall building increase because of shortage in land in urbanized areas. Due to sensitive structural system of high rise building, the lateral load for example wind load should be taken into consideration. In this research, four different shapes of high rise buildings have been chosen with $150 \mathrm{~m}$ in height (50 storeys) having $2500 \mathrm{~m}^{2}$ plan area. By using ETAB's 13.1.1v, the four shapes have been modeled which are elliptical, circular, rectangular and square. Various shapes have been compared with respect to different parameters such as storey drift, storey shear, axial force and displacement. As the result obtained in the paper, the percentage of peak shear storey reduced by $30.57 \%$ in rectangular shape, $68.37 \%$ in circular and $4.40 \%$ in elliptical shape with longitudinal direction of the gust factor in comparison with square shape of high rise building. The percentage of peak drift decreases in elliptical shape by $70.86 \%$ as well as it's more in both circular and rectangular by $1.27 \%$ and $14 \%$ respectively when compared with square shape of tall building. The percentage reduced in peak wind intensity by $68.392 \%$ and $4.471 \%$ for elliptical and circular shape respectively while in rectangular shape the percentage is more by $15 \%$. In addition, it was concluded the buildings which have elliptical or circular shape are more effective due to the smaller area which is perpendicular to the wind load direction and wind pressure will be less. Also, by changing the shape from square to elliptical shape the storey drift, storey shear, displacement and wind intensity decreased by maximum percentage (Gawali and Wakchaure 2015).

Once upon a time in $19^{\text {th }}$ century, there was no building as high rise building but because of the development in urban areas, there was a demand for vertical evolution of cities. During the design purpose of structure, the vertical load from gravity only considered but when the height of the building increases the horizontal load must be consider especially wind load which is more predominant. There are many tall buildings constructed and designed across the world in 1930 as well as many researches have been carried out in order to study the effect of wind load to the high rise building and how to reduce the effects. In this research, Computational Fluid Dynamic (CFD) method has been used in analysis of wind load. Auto CAD 3D software has been used for modeling seven different shapes of tall building having $110 \mathrm{~m}$ in height and plan area of $1250 \mathrm{~m}^{2}$. The seven shapes used in this study are circle, trapezium, flared, kite, star, swastika and tetragon. Gust factor method from dynamic wind force has been calculated according to IS875: part 3 standards and compare it with computational fluid dynamic drag force. It was found that, trapezium shape has less gust load and drag force while it's higher in swastika shape because angular edges hence it has high galloping influences near to the inlet near to edge. It was observed from this paper, that the more effective shape in reducing wind load through both drag force and gust load is circle building shape due to smooth surface which create less both friction and vortex shredding. Tetragon has large edges which lead to high galloping influence across edges. Flared building which has two edges is accountable for ultimate pressure and considered as more effective shape in reducing wind pressure more than circular shape. In addition, tetragon and trapezium have more 


\section{Journal of Student Research}

Fourth Middle East College Student Research Conference, Muscat, Sultanate of Oman

efficiency in reducing wind load than triangle which has high wind pressure. Trapezium has less drag force while the case of dynamic pressure the circular shape has very high value with maximum dynamic pressure. In brief, the swastika and circular shapes are much better in comparison with other building shape in reducing both drag force as well as pressure coefficient. Moreover, it's observed that the orientation of the building playing an essential role in reducing moment and gust load in order to reduce also wind load (Kulkarni and Lohade 2016).

Tall building has been designed either rectangular or square shapes but recently due to the development in urban area, the architecture engineers start to design high rise buildings with unconventional shapes. For designing buildings with response to wind load, the designer refers to standards on wind load AS/NZS: 1170.2-2002, BS: 63699-1995, ASCE: 7-02-2002, IS: 875 (Part 3), EN: 1991-1-4-2005 to carry out the force coefficient and pressure coefficient. In this paper, Y shape high rise building has been chosen with height of $500 \mathrm{~m}$. The parameters which have been studied in this literature review are, shear force (Fx), torsional moment (Mz) and overturning moment (Fy) which measured in single instrument. It was found that Fx maximum obtained at $225^{\circ}, 135^{\circ}, 105^{\circ}$ and $15^{\circ}$ because of entrapment of air and it's high exposed area while the minimum values which the air entrapment doesn't place at $180^{\circ}$ and $60^{\circ}$. Highest values of $\mathrm{Mz}$ at $195^{\circ}$ and $75^{\circ}$ while the lowest values at $165^{\circ}$ and $45^{\circ}$. Mz found to be 0 at $240^{\circ}, 180^{\circ}, 120^{\circ}, 60^{\circ}$ and $0^{\circ}$ because of the wind load acting parallel to the symmetrical axis of Y plan shape. It was concluded that tall building with Y shape is highly affected by the wind load (Ahlawat and Ahuja 2015).

The world is in rapid state of urban population and growth in architectural field of buildings as well as the structural system is sensible to wind load. Many researches have been done in order to reduce the excitation to wind load and improving the properties of high rise building. This study is about the effect of wind action to different shapes of high rise buildings with respect to some parameters which are drag force, wake region, wind pressure coefficient (WPC) and left force. There are various geometric plan shapes of high rise buildings as shown in figure 4.4 below with same plan area. Discussion and comparison of aerodynamic load measurement was conducted for different models of high rise buildings. It was found that the comparison of octagonal and hexagonal shape with blunt wind ward edge has more efficiency in mitigating wind pressure coefficient. Moreover, the octagonal shape with sharp wind ward edge is efficient than hexagonal shape in minimizing the wind pressure coefficient. In addition, square shape has maximum value of wind pressure coefficient while the minimum was in circular building shape. By comparing swastika shape with square, the swastika more efficient in reducing wind pressure coefficient while the drag force become more in swastika than square. Briefly, the shape of building is very important in reducing wind load effect in the sense of various design parameters should be considered before constructing the building. Finally, appropriate studies in this regard are indispensable before taking the consideration of any building shape (Roy et al. 2017).

The tall building structure designed in order to resist different types of loads such as lateral load resulting from earthquake and wind load. Wind generates three different types of effects on high rise building for example dynamic, static and aerodynamic. In a structural manner, static effect is a term in analyzing autonomous of time while the dynamic analysis is a trial to observe how the structural system response to the change through period of time. When the building is flexible, it will interact with the wind force and influence its response called aerodynamic effect. The dynamic responding of high rise building to the lateral load especially wind load is affected by many factors such as mass, structural stiffness, damping and architectural form and shape. There are two main solutions used in order to control the dynamic influence, which are structural and architectural. Architects can reduce wind load effect on high rise building by designing the shape of aerodynamically as well as using setbacks and tapering. In addition, by using aerodynamic modifications which classified into micro and macro modifications used also to reduce the cost of construction and the weight of structure. The structural engineers also can mitigate the influence of wind load to tall buildings by designing and choosing efficient structural system such as diagrid and tube. So, before constructing tall building an alternate design method should be introduced by creating innovative computational workbench in order to design efficient high rise building to resist 
wind load affect. Wind effect happens generally in two main ways of action which are along wind and across wind. For a rectangular shape building, the two faces are considered along wind direction and the other two is perpendicular faces to wind flow and considered as across wind. The geometry and shape of high rise buildings as well as the aerodynamic modification and facade of the building can mitigate the wind load effect (Alaghmandan et al. 2016).

In this paper, Comparison and analysis between four different building shapes have been carried out with 15, 30 and 45 storey by kept the plan area same $1296 \mathrm{~m}^{2}$. In addition, the parameters of the building have been obtained such as support and loading condition, beam and column, dead and live load, wind load as well as design parameters for example grade of steel and concrete. It was found that regarding to shapes which having more stability, the square shape in 45 storey, rectangular shape in 630 storey and triangle shape building in 15 storey. It was concluded from the results obtained in terms of node displacement that lower stable shapes found in rectangle shape in 45 storey building while triangle plan shape in both 15 and 30 storey. The analysis of maximum moment (Mz) and shear (Fy) have been organized in table below according to most stable shapes (Rajmani and Guha 2015).

\begin{tabular}{|l|l|l|}
\hline Storey/ parameters & Maximum moment (Mz) & Maximum shear (Fy) \\
\hline 15 & Triangular & Rectangular \\
\hline 30 & Rectangular & Circular \\
\hline 45 & Circular & Rectangular \\
\hline
\end{tabular}

Table 2. Results of maximum moment and shear in terms of most stable shape (Rajmani and Guha 2015).

This section will obtain the result and discussion for each building shape and different parameters. The result of analysis part will be illustrated by using Excel software for comparing data of buildings.

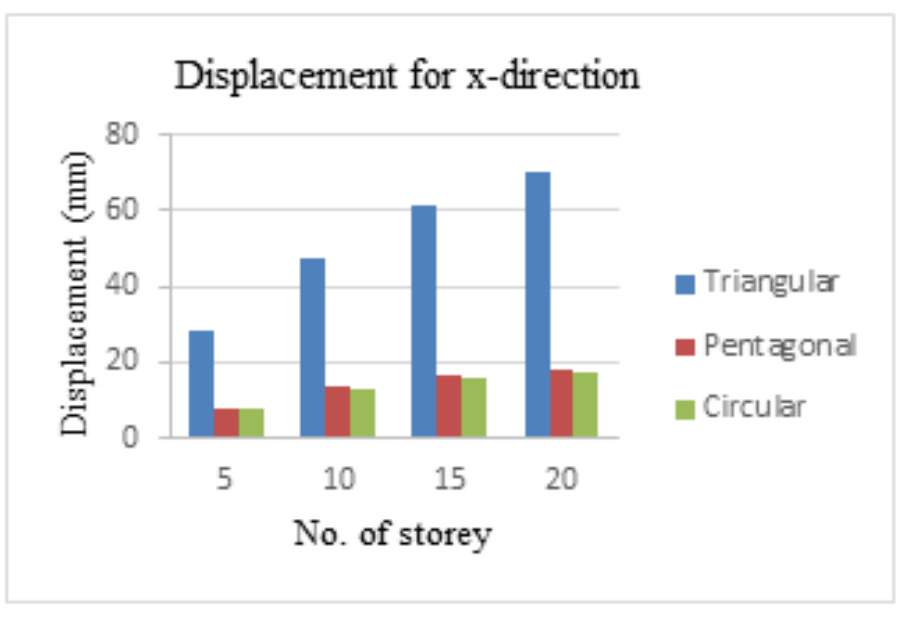

Figure 4. Storey displacement for all buildings at specified stories for X direction. 


\section{Journal of Student Research}

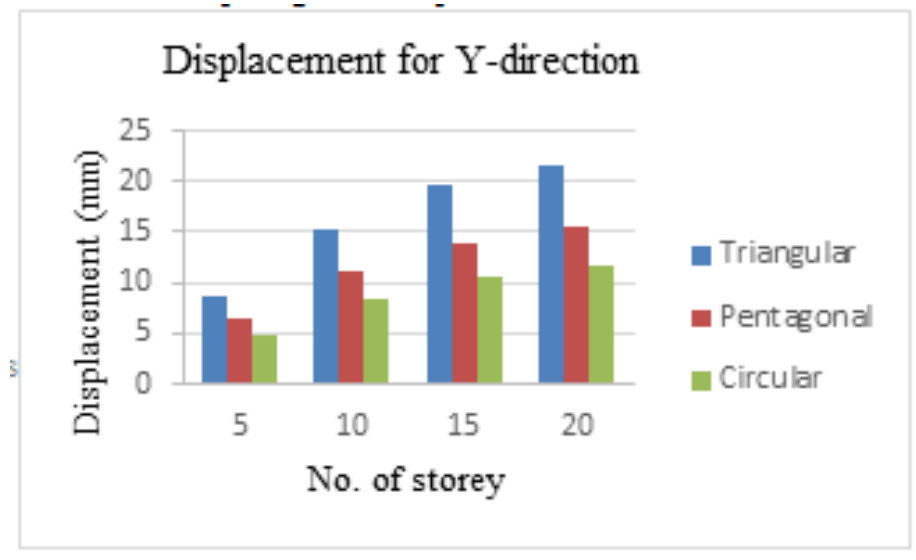

Figure 5. Storey displacement for all buildings at specified stories for Y direction.

The above two graphs illustrate the displacement values for all building shapes at 5, 10, 15 and 20 storey for $\mathrm{X}$ and $\mathrm{Y}$ directions of wind load. It is very clear that the order of the shapes in terms of the most displacement until the lower displacement is triangular, then pentagonal shape and the last one is the circular building shape that having the minimum value of displacement. Also, it can be noted down that there is a high difference between circular and pentagonal shape in Y direction while small difference at the $\mathrm{X}$ direction. This is because when the wind load acting on small area the displacement will more but when it's distributed over large area the displacement will reduced. Finally, the circular shape is considered the best shape in terms of less displacement response to wind load. In general, it's noted that the structures must have more strength and stiffness in X direction in order to minimize the displacement and to make the structure having more stability and resistance to the impact of wind load.

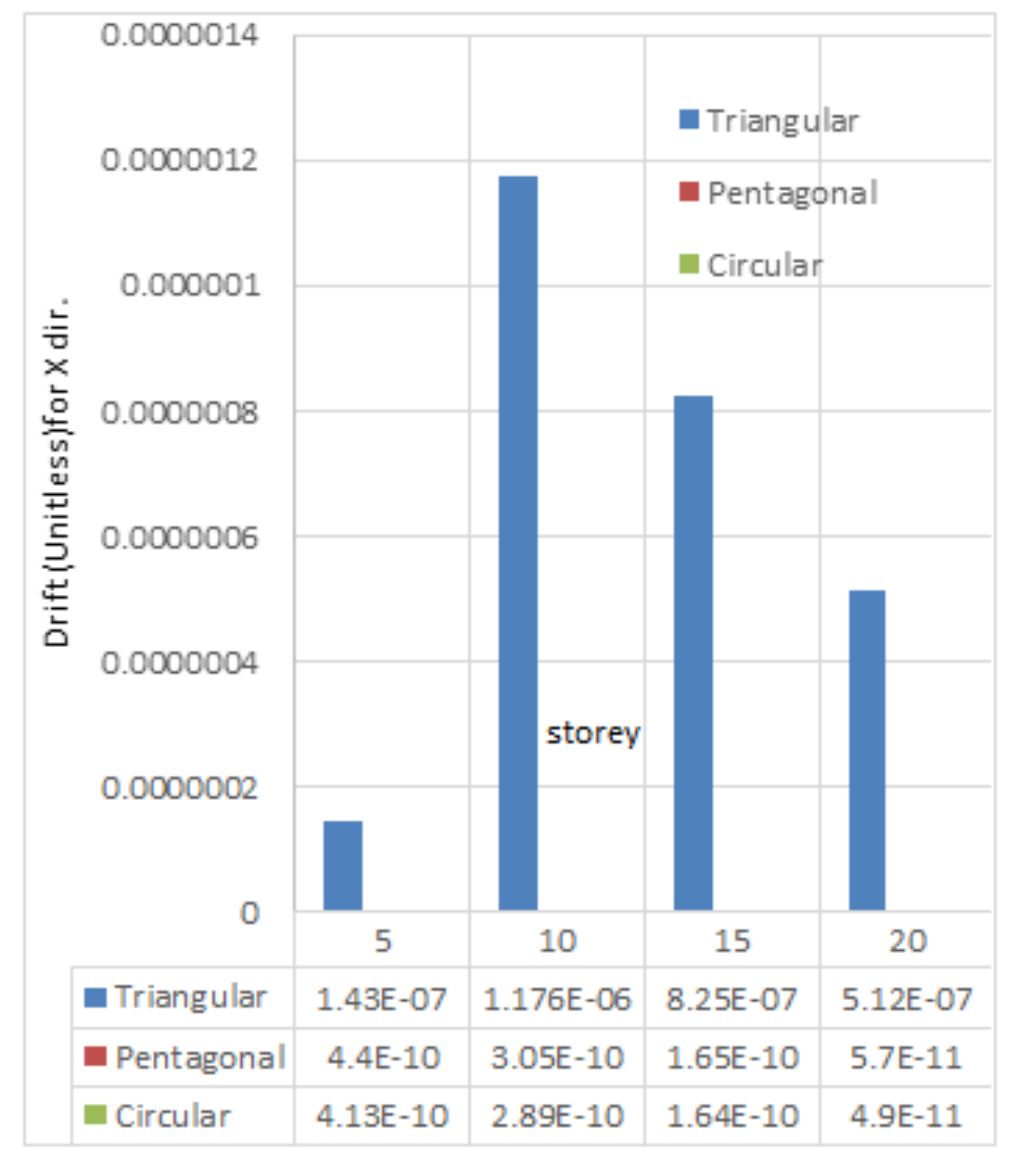


Figure 6. Storey drift for all buildings at specified storeys for X direction.



Figure 7. Storey drift for all buildings at specified storeys for Y direction.

The above plotted graphs shows the drift values for all buildings at specified storeys $(5,10,15$ and 20 storey). It's noted down that the triangular building shape has more drift value that refer to less stiffness in triangular shape in comparing with other shapes. The designers must provide appropriate structural system in order to reduce the induced wind load. In addition, it observed that the minimum value of drift appearing to circular shape because it has lower wind load pressure affect the building elevation. The pentagonal shape has less drift value than triangular shape and more than circular shape due that area affected building elevation from wind pressure.

\section{Conclusion}

Each tall building is unique and based on many situations which influence the choice made in the design of high rise buildings. It was concluded that, before constructing tall buildings an alternate design method should be introduced by creating innovative computational workbench in order to design efficient high rise building to withstand wind load influences. High rise buildings are affected by wind load through deferent parameters such as storey drift, shear force, displacement, bending moment, axial force etc. The wind load affects increases with increasing the height of the building. Many researchers carried out papers to study the effect of lateral load on tall building and find a proper solution to avoid instability of structure. In order to reduce those effects the suitable structural system and the frontage of the building should be well chosen. Also, the appropriate choice of building shape and architectural modifications are frequently effective to reduce wind load by changing the flow pattern in surrounding of the building. In addition, the geometry and aerodynamic modification contribute to make the building having more stability and strength. At the end, the structures must be designed for forces obtained in different directions for critical forces of earthquake or wind to prevent damage in building which leads to collapse. Modern buildings having high efficient structural system depending on the number of storey designed. In addition, these advanced buildings provided by qualified materials due to the sensitivity of the building when exposed to the lateral loads effects. Therefore, developing the criteria of the building through providing the appropriate structural system will contribute in reducing the impact of wind load on high rise building. The objectives of this project has been achieved through studying the behavior of different shapes of building when subjected to wind load. As well as, the comparison of all shapes carried out to choose the most stable building. The conclusion of this study has been summarized in following point:

- The shape of the tall buildings playing a major role in reducing the wind load effect in terms of different design parameters that should be taken into consideration before designing any 
building.

- The orientation of the building is important in mitigating the lateral load here wind load. Moreover, the structures should be designed and constructed for forces obtained in various directions for critical forces of earthquake or wind load.

- If the building height increased, the lateral load comes from wind load will increased as well causing the increasing in wind pressure. This is will generate additional stress to the building members. In addition, the storey displacement increased so the structure will have less stability and stiffness.

- The circular shape building is more effective and less affected by wind load because of smooth surface that create a less friction between the wind load and the surface itself due to the wind excitation.

- By changing the shape from triangular to circular shape, the storey displacement and drift will reduced by maximum percentage due to reducing the wind pressure affecting the building.

- The building shapes that highly influenced by wind load can be reduced the impact by taking the efficient structural system, lateral bracing and increasing the dimension of beam and columns to have enough stiffness as well as usually shear wall has been used in order to reduce wind load.

This study is connected to the scholars studies through result getting from this report is matched with the journals and the result of literature review chapter. At the end, I hope my findings in this project are expanded the knowledge in this field as well as contributes to all of us in future and done in required manner.

\section{Acknowledgements}

I would like to express my thanks for all people who help me to complete the project report in acceptable manners and in the required goals. My thanks and appreciation for my supervisor Mr. Himanshu Gaur for his guidance. My special thanks to Mr. Suchain, for his guidance and help. I am extremely thankful to Dr. Ram Kishore, Head of Civil Engineering Department for giving me recommendations regarding the project. I would like to express my deepest sense of respect to my brother Mr. Abdullah Al-Azri, Urban planning in Ministry of housing for motivating and helping me.

\section{References}

Ahlawat, R., and Ahuja, A. (2015). "Wind loads on ' $\mathrm{Y}$ ' plan shape tall building." Engineering and Applied Sciences. 2 (4): 80-783.

Alaghmandan, M., Elnimeiri, M., Krawczyk, R., and Buelow, P. (2016). "Modifying tall building form to reduce the along wind effect." council on tall building and urban habitat. 2 (2): 1-7.

Al-Nuaimi, A.S., Mohsin, M.A., and Al-Riyami, K.H. (2014). "A Basic Wind Speed Map for Oman." Engineering Research. 11 (2): 64-7.

Gawali, S., and Wakchaure, R., (2015). "Effect of shape on wind forces of high rise buildings using Gust Factor Approach.” Science, Engineering and Technology Research. 4 (8): 2979-2987.

Kulkarni, S., and Lohade, S., (2016). "Shape effects of wind induced response of tall buildings using CFD." Engineering and Applied Sciences 6 (3): 25-28. 
Patil, S.J., Mali, M.Z., and Talikoti, R.S. (2015). "Effect of wind load on high rise structure." Engineering and Technical Research 7 (3): 384-386.

Rajmani, A., and Guha, P. (2015). "Analysis of wind \& earthquake load for different shapes of high rise building." Civil Engineering and technology 6 (2): 38-45.

Roy, A., Sharma, A., Mohanty, B., and Singh, J. (2017). “Wind loan on high rise building with different configurations." institute of technology 6 (2) 372-379.

Sagar, Y.A., Reddy, V.B., Vasam, S.N., and Reo, S.P. (2015). "Effect of wind forces on multistoreyed structures." Innovative Research in Advanced Engineering 2 (6), 79-83. 